\title{
KINETIC CHARACTERIZATION OF THE FIRST PEAK OF NATURAL FLUORITE FROM LOW DOSE $\beta$-IRRADIATION
}

\author{
Latif, M.B. ${ }^{1, *}$, Aborisade, C.A. ${ }^{2}$, Fasasi, M.K. ${ }^{1}$ and Balogun, F.A. ${ }^{1}$ \\ ${ }^{1}$ Division of Applied Nuclear Science and Technology, Centre for Energy Research and Development, Obafemi \\ Awolowo University, Ile-Ife 220005, Nigeria. e-mail: mlatif@cerd.gov.ng (M.B. Latif); mfasasi@cerd.gov.ng (M.K. \\ Fasasi); fbalogun@cerd.gov.ng (F.A. Balogun) \\ ${ }^{2}$ Department of Physics and Engineering Physics, Obafemi Awolowo University, Ile-Ife 220005, Nigeria. \\ caboris@,oauife.edug.ng (C.A. Aborisade) \\ *Corresponding author e-mail: mlatif@cerd.gov.ng \\ (Received: 14th September, 2017; Accepted: 24th February, 2018)
}

\section{ABSTRACT}

\begin{abstract}
The low temperature peak (PI) of natural fluorite which occurs at $94^{\circ} \mathrm{C}$ at the heating rate of $\beta=1^{\circ} \mathrm{Cs}^{-1}$ exhibits complexity both in terms of shape and position as the absorbed dose is varied. The short lifetime of this peak makes it a good case for testing the existing thermoluminescence kinetic models. In this paper, the kinetic parameters of PI, namely the activation energy, $E_{A}$, the frequency factor, $S$, and the order of kinetics, $b$, have been evaluated using general order kinetics. Fluorite samples were irradiated with a low dose-rate $\left(40 \mu \mathrm{Gys}^{-1}\right) \beta$ irradiation source to a test dose of $1.2 \mathrm{mGy}$ and the heating rates of $\beta=1,3$ and $5{ }^{\circ} \mathrm{Cs}^{-1}$ were considered, in order to minimize the effect of temperature lag. The role of thermal quenching ( $W$ ) was investigated by evaluating the activation energy using the initial rise (IR) method for each of the heating rates. The obtained values of kinetic parameters are $E_{\mathrm{A}}=(1.31 \pm 0.06) \mathrm{eV}$ and $S=(8.34 \pm 1.00) \times 10^{16} \mathrm{~s}^{-1}$ while values of $b$ ranging from above 1.0 up to 1.4 were in good agreement. The value of $W=(0.30 \pm 0.04) \mathrm{eV}$ was obtained for the thermal quenching function and its contribution was found to be most significant at the heating rate of $\beta=5 \mathrm{C} \mathrm{s}^{-1}$.
\end{abstract}

Keywords: low-dose $\beta$-irradiation, first peak of natural fluorite, general-order kinetics, thermal quenching function, peak lifetime.

\section{INTRODUCTION}

Investigation of the thermoluminescence (TL) properties of inorganic materials allows not only for identifying potential candidates for retrospective dosimetry (Mesterházy et al., 2012; Katona et al., 2007; Osvay and Deme, 2006), but also for a better understanding of the properties of both naturally occurring and synthetic materials that are already being explored for the purpose. The fundamental requirements for a phosphor material to be used as a thermoluminescence dosimeter (TLD) include: (i) easily resolvable glow curves (ii) a linear relationship between TL output and the absorbed dose over a wide range and (iii) the ability to store the TL output over a reasonably long period when stored in a lightproof environment at ambient temperature (Oberhofer and Schermann, 1981). Also, the parameters that characterize the dynamics of electron-hole excitation and the interplay that govern their trapping during irradiation and release during heating, known as kinetic parameters are often evaluated. Although these parameters are primarily used to evaluate the stability of the TL signal (Chen et al., 2016), they also give an indication of the energy band diagram of the material particularly in the case of synthetic TLDs whereby the crystal structure as well as the dopant concentration which either acts as an enhancer or a quencher, are also known. In the case of naturally occurring TLDs however, e.g. fluorite, muscovite (Ige et al., 2006b), dolerite (Ogundare et al., 2006) among others, in which case various trace elements are present in the matrix of the main constituent (Balogun et al., 1997; Mokobia et al., 2008; Ige et al., 2006a), a simplified energy band diagram may not be applicable. For those cases, the standard thermoluminescence kinetic models may not be applicable either. More often, rather a glow-curve fitting approach has been a reliable way of extracting kinetic parameters.

The thermoluminescence kinetic models for analyzing glow-curves were first introduced in the mid-1940's (McKeever, 1988; Chen and McKeever, 1997). The first order (FO) kinetic model was the first of such models to be adopted and was introduced by Randall and Wilkins (Randall and Wilkins, 1945). It assumes that when 
free charge carriers are created during irradiation and trapped at defect centers, that they are released during heating and recombine at luminescence centers with zero probability of being re-trapped. Shortly after, came the second order (SO) kinetic which was introduced by Garlick and Gibson (Garlick and Gibson, 1948) and based on the assumption that the charge carriers of the FO model have equal probability of either being re-trapped or recombine at luminescence centers. Then in 1964 came the concept of general order kinetics which was introduced by May and Partridge (May and Partridge, 1964) to address non-FO and non-SO cases as measured glow-curves hardly obeyed those models. Besides, among the well-established techniques for evaluating kinetic parameters of thermoluminescence glow-curves are the initial rise (IR) method and the variable heating rate (VHR) method. While the VHR technique was originally conceived for FO situations, it was later extended to general order cases. The IR on the other hand, can be applied without prior knowledge of the kinetic model that best describes the glow-curves. It is based on the premise that the exponential-shaped part of the low temperature tail of the glow-curve also known as the initial rise region is exponentially dependent on the temperature (Garlick and Gibson, 1948). If the temperature at which the sample is being heated is low enough for the initial concentration of the carriers to be assumed constant, the TL intensity, $I$ is related to the temperature as:

$I=A e^{-\left(\frac{E_{I R}}{k T}\right)}$

where $A$ is a constant and $E_{I R}$ is the thermal quenching affected activation energy. Hence, a plot of $\ln (I)$ as a function of $1 / k T$ over the initial rise region corresponding to $\sim I=0$ up to $10 \%$ of the resonant intensity yields a straight line whose slope is $E_{\mathrm{IR}}$. In the case of the VHR method, the only parameter needed is the temperature at the resonant intensity $\left(T_{\mathrm{M}}\right)$ while a linear heating rate is required. It was first suggested by Hoogenstraaten (Hoogenstraaten, 1958) for a FO scenario. Heating rates are varied and the corresponding values of $T_{\mathrm{M}}$ are recorded. A plot of

$\ln \left(T_{M}^{2} / \beta\right)$ as a function of $1 / k T_{M}$ yields a straight line whose slope and intercept are $E_{\mathrm{A}}$ and $\ln (E / S k)$ respectively. The concept was later extended to the general order case by Chen and Winer (Chen and Winer, 1970) to arrive at the expression:

$$
\beta E_{A} / k T_{M}^{2}=S\left[1+(b-1) \nabla_{M}\right] \exp \left(-E_{A} / k T_{M}\right),(2)
$$

where

$$
\nabla_{M}=\frac{2 k T_{M}}{E_{A}}
$$

with the assumption that $\left[1+(b-1) \nabla_{M}\right]$ is constant.

In a general order case, the IR can only be used to determine the activation energy (McKeever, 1988; Chen and McKeever, 1997) whose value may be affected by thermal quenching and the presence of a satellite peak. The VHR on the other hand does not suffer the effect of thermal quenching although it requires that peak positions be clearly identified. Hence applying these two techniques complementarily allows for an efficient evaluation of the activation energy as well as the thermal quenching function.

Calcium fluoride $\left(\mathrm{CaF}_{2}\right)$ is one of a few crystals with good thermoluminescence properties both in natural form as well as in synthetic form. It has therefore attracted a lot of attention due to its high sensitivity to ionizing radiation (Yazici et al., 2002; Maghrabi et al., 2003; Polymeris et al., 2006; Tugay et al., 2009; Bidyasagar et al., 2014; Topaksu et al., 2016). The low temperature peak of natural fluorite identified as PI in Latif et al. (2012) was observed to be shifting towards higher temperatures with increasing absorbed dose when readout at the heating rate of $5^{\circ} \mathrm{C} \mathrm{s}^{-1}$ for a dose range of $40 \mu \mathrm{Gy}-72 \mathrm{mGy}$. This peak has successfully been decomposed into two distinct peaks using computerized glow curve deconvolution approach especially when readout at the heating rate of $1^{\circ} \mathrm{C} \mathrm{s}^{-1}$ (Topaksu and Yazici, 2007; Tugay et al., 2009). An examination of this convoluted peak may be of interest for all practical purposes. Although this peak may not be adequate for dosimetric applications due to its short lifetime, accurate evaluation of its kinetic parameters may be tasking. Besides, the high temperature peaks which are relatively more stable and have longer lifetimes have had their kinetic parameters evaluated by Ogundare et al. (2004). 
This paper seeks to report the kinetic parameters of PI from a fluorite taken from Nigeria for the first time. The variable heating rates and the initial rise methods were used to evaluate the activation energy in a bid to account for the magnitude of the thermal quenching function. The former method was used to determine the frequency factor and a good approximation of the order of kinetics.

\section{METHOD}

Fluorite samples obtained from Nigeria (MiddleBenue) was prepared as described in Balogun et al. (1999). They were thereafter milled into fine powders using a standard ring mill. The samples were annealed for $1 \mathrm{~h}$ at $400^{\circ} \mathrm{C}$ inside a standard TLD oven and then allowed to cool slowly therein to room temperature. They were thereafter irradiated with a low dose-rate $\left(40 \mu \mathrm{Gy} \mathrm{min}^{-1}\right)$ ${ }^{90} \mathrm{Sr} /{ }^{90} \mathrm{Y} \beta$-irradiation source (model 2210 Thermo Fisher Scientific). The TL readout was carried out using a model 3500 Harshaw TLD reader and samples were heated from a preheat temperature of $50^{\circ} \mathrm{C}$ to a maximum of $146 \mathrm{C}$ where PI fully occurs. The glow curves were acquired at the heating rates of $1^{\circ} \mathrm{C} \mathrm{s}^{-1}, 3^{\circ} \mathrm{C} \mathrm{s}^{-1}$ and $5^{\circ} \mathrm{C} \mathrm{s}^{-1}$. This was done with a view to minimizing the effects of temperature lag between the heating element of the reader and the samples. This is a well-known factor that affects evaluated kinetic parameters and has been extensively discussed (Furetta et al., 1997; Kitis and Tuyn, 1998). This is addressed here by using relatively low heating rates from $\beta=$ $1-5^{\circ} \mathrm{C} \mathrm{s}^{-1}$. This effect is further minimized when the samples are in fine powder forms (Ogundare $e t$ al., 2004). The kinetic parameters of PI are determined using the IR and the VHR methods.

\section{IR method}

The IR was applied to the acquired glow curves by selecting the appropriate initial rise region in which the TL intensity is less or equal to $10 \%$ of the TL intensity at the resonant temperature for each of the heating rates considered. By taking the natural logarithm of the Eq. (1), one can write:

$$
\ln (I)=\ln (A)-E_{I R} / k T
$$

such that a plot of $\ln$ (I) against $1 / k T$ yields a straight line of slope $E_{\mathrm{IR}}$ and intercept $\ln (A)$. For each of the three heating rates, the obtained straight lines' equations are as listed below:

$$
\begin{aligned}
& \beta=1^{\circ} \mathrm{C} \mathrm{s}^{-1}: \ln (I)=39.89-1.01(1 / \mathrm{kT}), \\
& \beta=3^{\circ} \mathrm{C} \mathrm{s}^{-1}: \ln (I)=38.34-1.06(1 / \mathrm{kT}),(5) \\
& \beta=5^{\circ} \mathrm{C} \mathrm{s}^{-1}: \ln (I)=42.39-0.97(1 / \mathrm{kT}),
\end{aligned}
$$

\section{VHR method}

The resonant temperatures were recorded from each of the glow curves and the obtained values are $T_{M}=94^{\circ} \mathrm{C}, 104^{\circ} \mathrm{C}$ and $108^{\circ} \mathrm{C}$ for $\beta=1{ }^{\circ} \mathrm{C} \mathrm{s}^{-1}, 3^{\circ} \mathrm{C}$ $\mathrm{s}^{-1}$ and $5^{\circ} \mathrm{C} \mathrm{s}^{-1}$, respectively.

In analogy to the FO expression, Eq. (2) can be rewritten as:

$\frac{T_{M}^{2}}{\beta}=\frac{E_{A}}{k S\left[1+(b-1) \nabla_{M}\right]} \exp \left(E_{A} / k T_{M}\right)$.

The natural logarithm of Eq. (6) gives:

$\ln \left(\frac{T_{M}^{2}}{\beta}\right)=\ln \left(\frac{E_{A}}{k S\left[1+(b-1) \nabla_{M}\right]}\right)+\frac{E_{A}}{k T_{M}} .(7)$

Thus, a plot of $\ln \left(\frac{T_{M}^{2}}{\beta}\right)$ against $\frac{1}{k T_{M}}$ yields a straight

line of slope $E_{\mathrm{A}}$ and intercept $\ln \left(\frac{E_{A}}{k S\left[1+(b-1) \nabla_{M}\right]}\right)$

For the measured resonant temperatures and their corresponding heating rates, the following equation was obtained:

$\ln \left(\frac{T_{M}^{2}}{\beta}\right)=-29.481+1.31\left(\frac{1}{k T_{M}}\right)$.

The frequency factor, $S$ can then be derived by comparing Eqs. (7) and (8) term by term as:

$S=\frac{E_{A}}{k e^{-29.481}\left[1+(b-1) \frac{2 k T_{M}}{E_{A}}\right]}$.

The value of Boltzmann's constant was taken to be $k=8.6173 \times 10^{-5} \mathrm{eV} \mathrm{K}^{-1}$.

\section{Thermal quenching}

Activation energy values derived using the IR method are affected by thermal quenching which is generally conceived as a reduction in luminescence efficiency as a function of the temperature. The luminescence efficiency can be expressed as (McKeever, 1988):

$\eta=\frac{1}{1+\operatorname{Cexp}\left(-\frac{W}{k T}\right)}$,

where $C$ is a dimensionless constant and $W$ (in eV) is thermal quenching function. The thereof derived activation energy is generally written as: 
$E_{I R}=E_{A}-W$.

The determination of the activation energy using the VHR method allows for accounting for the thermal quenching for each of the heating rates used. Moreover, the lifetime of a charge carrier in the metastable state may then be determined with more accuracy using the F.O. expression (McKeever, 1988):

$\tau=S^{-1} \exp \left(\frac{E_{A}}{k T_{s}}\right)$,

where $T_{\mathrm{s}}$ is the storage temperature.

\section{RESULTS AND DISCUSSION}

Figure 1 shows the glow curves of the first peak of natural fluorite (PI) for the three heating rates $(\beta$ $=1,3$ and $5^{\circ} \mathrm{C} \mathrm{s}^{-1}$ ) considered. In order to prevent the effect of shape deformation on this peak by the high temperature peaks which are more prominent, PI was isolated and acquired from the recommended pre-heat temperature of the TL reader of $50^{\circ} \mathrm{C}$ to a maximum temperature of $146^{\circ} \mathrm{C}$ whereby the peak is fully formed irrespective of the heating rate. As expected, the glow peak position shifts towards higher temperature with increasing heating rates and was recorded at $\mathrm{T}_{\mathrm{M}}=94^{\circ} \mathrm{C}, 104^{\circ} \mathrm{C}$ and $108^{\circ} \mathrm{C}$ for the heating rates of $\beta=1^{\circ} \mathrm{C} \mathrm{s}^{-1}, 3^{\circ} \mathrm{C} \mathrm{s}^{-1}$ and $5^{\circ} \mathrm{C} \mathrm{s}^{-1}$, respectively. Also, the TL intensity decreases with increasing heating rates and had the values of 668, 632 and 529 for $\beta=1^{\circ} \mathrm{C} \mathrm{s}^{-1}, 3^{\circ} \mathrm{C} \mathrm{s}^{-1}$ and $5^{\circ} \mathrm{C} \mathrm{s}^{-1}$, respectively. This is known as a reduction in luminescence efficiency with increasing heating rate. It can be observed that the reduction in peak intensity from $\beta=1{ }^{\circ} \mathrm{C} \mathrm{s}^{-1}$ to $\beta=3^{\circ} \mathrm{C} \mathrm{s}^{-1}(5.38 \%)$ is less pronounced as against the reduction in peak intensity from $\beta=3^{\circ} \mathrm{C} \mathrm{s}^{-1}$ to $\beta=5^{\circ} \mathrm{C} \mathrm{s}^{-1}(16.30 \%)$. The reduction in luminescence intensity at higher heating rates also accounts for the seeming disappearance of the satellite peak that occurs around $113^{\circ} \mathrm{C}$ at the heating rate of $\beta=1{ }^{\circ} \mathrm{C} \mathrm{s}^{-1}$ for the glow curves acquired at $\beta=3^{\circ} \mathrm{Cs}^{-1}$ and $5^{\circ} \mathrm{Cs}^{-1}$. The activation energy values derived from the IR method are extracted from Eq. (5) and have the values $1.01,1.06$ and $0.97 \mathrm{eV}$ for $\beta=1^{\circ} \mathrm{C} \mathrm{s}^{-1}, 3^{\circ} \mathrm{C}$ $\mathrm{s}^{-1}$ and $5^{\circ} \mathrm{C} \mathrm{s}^{-1}$, respectively and an average value of $\mathrm{E}_{\mathrm{IR}}=(1.01 \pm 0.04) \mathrm{eV}$.

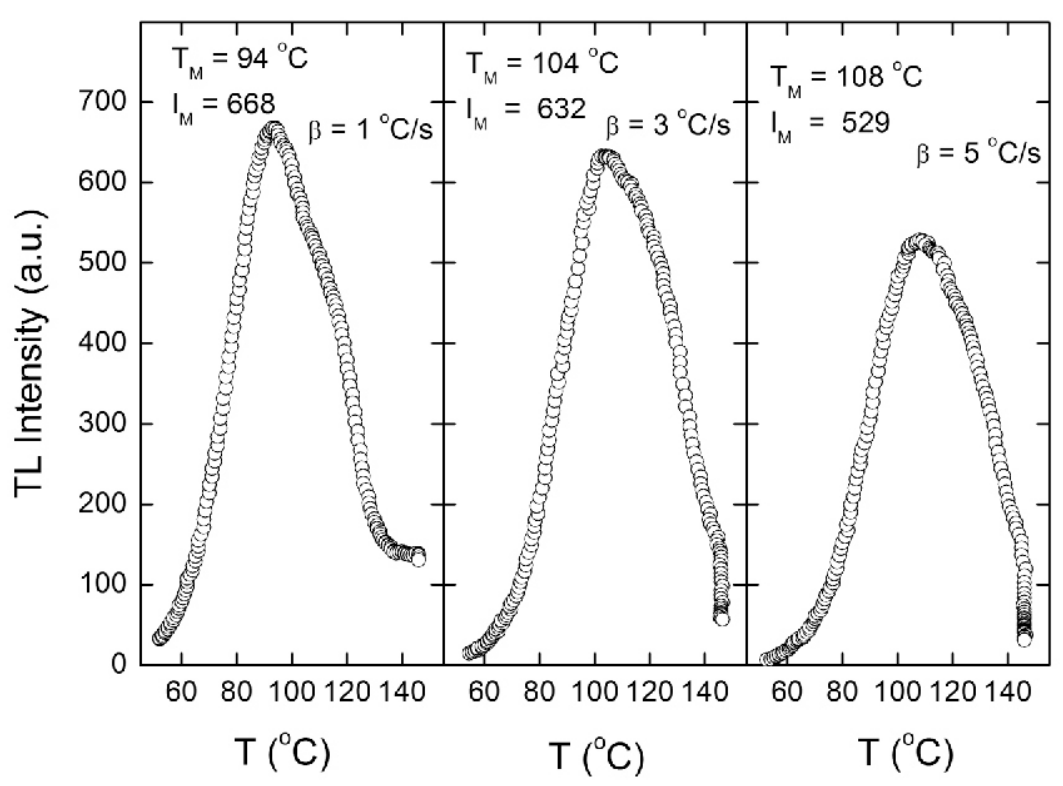

Figure 1: Glow curves of the first peak of fluorite (PI) acquired in the temperature range of $50-146^{\circ} \mathrm{C}$ at the heating rates of $1^{\circ} \mathrm{C} \mathrm{s}^{-1}, 3^{\circ} \mathrm{C} \mathrm{s}^{-1}$ and $5^{\circ} \mathrm{C} \mathrm{s}^{-1}$. As expected, peak intensity decreases while peak position shifts towards higher temperature with increasing heating rates.

The plot of $\ln \left(\frac{T_{M}^{2}}{\beta}\right)$ against $1 / k T_{M}$ for the heating rates considered and their corresponding maximum peak temperatures is shown in Fig. 2. 


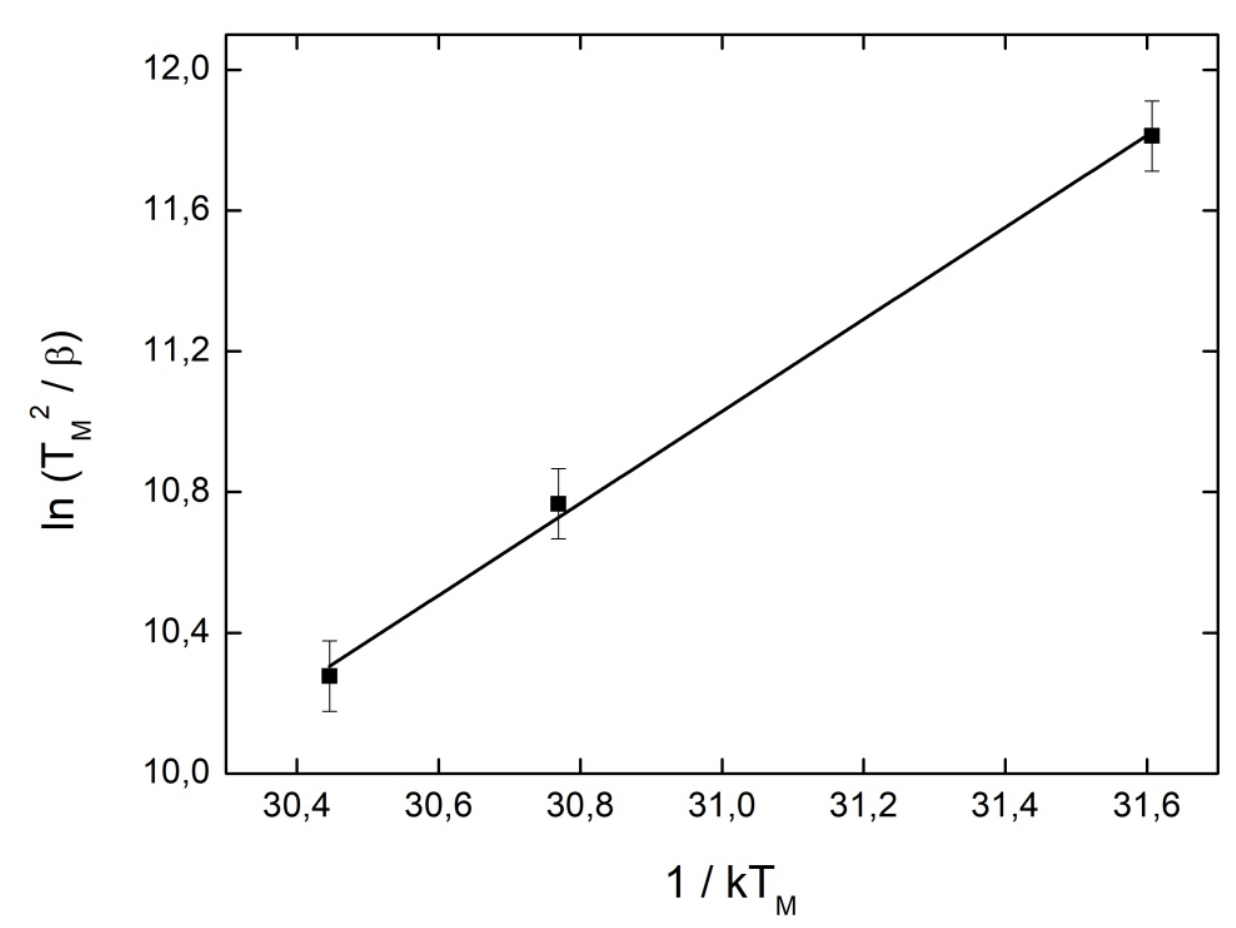

Figure 2: Linear fit of plot of $\ln \left(\frac{T_{M}^{2}}{\beta}\right)$ against $1 / k T_{M}$ for the peak positions of $\mathrm{T}_{\mathrm{M}}=94,104$ and $108^{\circ} \mathrm{C}$ and the heating rates of $\beta=1,3$ and $5^{\circ} \mathrm{C} \mathrm{s}^{-1}$, respectively.

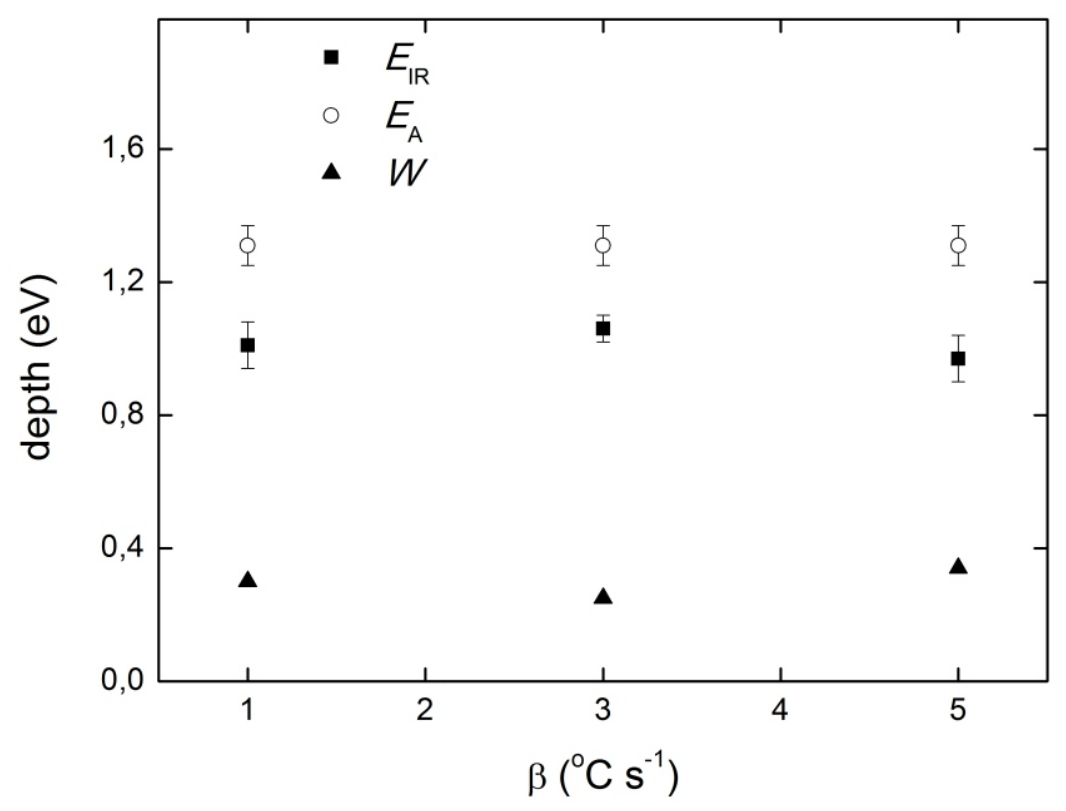

Figure 3: A plot of the activation energy computed using the IR method $\left(E_{\mathrm{IR}}\right)$ and the corresponding thermal quenching value as a function of the heating rates together with the actual trap depth $\left(E_{\mathrm{A}}\right)$.

The corresponding fit parameters are given by Eq. (8) from which the activation energy is deduced to be $E_{\mathrm{A}}=1.31 \pm 0.06 \mathrm{eV}$. The thermal quenching function can then be derived for each of the heating rates from Eq. (11) to be $W=0.30,0.25$ and $0.34 \mathrm{eV}$ respectively for the heating rates of $\beta$

\begin{abstract}
$=1^{\circ} \mathrm{C} \mathrm{s}^{-1}, 3^{\circ} \mathrm{C} \mathrm{s}^{-1}$ and $5^{\circ} \mathrm{C} \mathrm{s}^{-1}$ with an average value of $W=(0.30 \pm 0.04) \mathrm{eV}$. A distribution of the activation energy values computed using the IR method together with their corresponding thermal quenching function values is shown in Fig. 3. As it can be seen from that figure, there is no
\end{abstract}


systematic reduction in the trap depth with increasing heating rates. The thermal quenching function rather has its highest value at the heating rate of $\beta=5^{\circ} \mathrm{C} \mathrm{s}^{-1}$ which indicates an increased probability of non-radiative recombination at the luminescence centers responsible for PI, which compete with the radiative recombination. In fact, the luminescence efficiency computed using Eq. (10) which is indirectly dependent on the heating rates since peak temperatures are affected by the heating rate used, shows that the highest value of $\eta$ $=0.1$ is obtained for $\beta=3^{\circ} \mathrm{C} \mathrm{s}^{-1}$ as against $\eta=0.022$ and $\eta=0.008$ for $\beta=1^{\circ} \mathrm{C} \mathrm{s}^{-1}$ and $\beta=5^{\circ} \mathrm{C} \mathrm{s}^{-1}$, respectively if one assumes the dimensionless constant to be $C=1$. The applicability of the IR method requires that the IR region be carefully selected. The activation energy computed using this method may be affected by the presence of a satellite peak in the lower temperature half of the glow curve. These requirements were observed for each of these heating rates. The satellite peak which is only apparent at $\beta=1{ }^{\circ} \mathrm{C} \mathrm{s}^{-1}$ occurs in the other half of the glow curve and therefore has no effects on $E_{\mathrm{IR}}$. The activation energy value obtained using the VHR which is a true reflection of the trap depth for PI and has a value of $E_{\mathrm{A}}=$ $1.31 \pm 0.06 \mathrm{eV}$ is comparable with the value $1.20 \pm$ $0.01 \mathrm{eV}$ reported by Topaksu and Yazici (2007) using the $T_{\mathrm{M}}-T_{\text {Stop }}$ method. The role of thermal quenching which is assumed to be negligible for low temperature peaks as observed in quartz by Wintle (1975) is quite noticeable in PI which only occurs at $94^{\circ} \mathrm{C}$ for $\beta=1{ }^{\circ} \mathrm{C} \mathrm{s}^{-1}$. This is an indication of some thermal instability of this peak. The continuous shifting of this peak towards higher temperature when the absorbed dose is increased can be interpreted as the effect of saturation of a low temperature component while other components are excited by higher doses causing the convoluted peak to shift towards higher temperature. El-Kolaly (1977) shows that luminescence intensity in natural $\mathrm{CaF}_{2}$ decreases sharply in the lower temperature region up to $100^{\circ} \mathrm{C}$ which corresponds to the region where PI occurs and increases steadily afterwards. Nambi (1978) interpreted it as the effect of thermal quenching due to dominance of electron trapping in that temperature range. This effect may not be present in the higher temperature peaks of fluorite.

A major challenge associated with the use of the VHR for determining trapping parameters is that the computed value of one parameter is used to determine the other. Generally, the activation energy is determined independently while its value has a direct influence on the attempt-to-escape frequency, commonly referred to as the frequency factor, S. In a general order case, a prior knowledge of the order of kinetic $b$ is assumed then $S$ can be determined by combining Eqs. (7) and (8). Chen and Winer (1970) assumed that the term in square-brackets is constant, that is to say slight changes in it would not affect the reliability of the frequency factor thereof derived. The term $\nabla_{\mathrm{M}}$ defined in Eq. (3) has the values of $\nabla_{\mathrm{M}}=$ $0.0560,0.0575$ and 0.0581 for $\beta=1^{\circ} \mathrm{C} \mathrm{s}^{-1}, 3^{\circ} \mathrm{C} \mathrm{s}^{-1}$ and $5^{\circ} \mathrm{C} \mathrm{s}^{-1}$, respectively. If one assumes any $b$ values ranging between 1.001 and 1.999 for example, the term in square brackets ranges between 1.000 and 1.058 for these heating rates. Hence, one can determine the value of $S$ by equating the term in square brackets to unity. Using Eq. (9) one obtains $S=(8.34 \pm 1.00) \times 10^{16} \mathrm{~s}$ ${ }^{1}$. The lifetime of a charge carrier in the metastable state can then be derived using Eq. (12) and for $T_{\mathrm{S}}$ $=20{ }^{\circ} \mathrm{C}$ one obtains approximately $\tau=5$ days which implies that PI would have totally faded away within a few tens of days. The frequency factor value herewith obtained may be considered effective (Chen et al., 2016) since it falls outside the typical Debye frequency range (Mott, 1948). Were the value of $S$ two orders of magnitude lower, to be in the lattice vibration frequency range, a corresponding lifetime value in the range of $\tau \approx$ 1.3 years would be obtained as against what has been practically observed with PI (Balogun et al, 1999; Topaksu and Yazici, 2007; Latif et al., 2012).

The kinetic parameters derived using both the IR and the VHR approaches are summarized in Table 1. 
Table 1: Kinetic parameters derived from the glow curves using the initial rise (IR) and the variable heating rates (VHR) methods

\section{IR}

\begin{tabular}{ccc}
\hline$\beta\left({ }^{\circ} \mathrm{C} \mathrm{s}^{-1}\right)$ & $E_{\mathrm{IR}}(\mathrm{eV})$ & $\mathrm{W}(\mathrm{eV})$ \\
\hline 1 & $1.01 \pm 0.07$ & $0.30 \pm 0.07$ \\
3 & $1.06 \pm 0.04$ & $0.25 \pm 0.04$ \\
5 & $0.971 \pm 0.07$ & $0.34 \pm 0.07$ \\
Mean & $1.01 \pm 0.04$ & $0.30 \pm 0.04$ \\
\hline \multicolumn{2}{c}{$\mathrm{VHR}$} \\
\hline$E_{\mathrm{A}}(\mathrm{eV})$ & & \\
\hline $1.31 \pm 0.06$ & & $\left.(8.34 \pm 1.00) \times 1 \mathrm{~s}^{-1}\right)$ \\
\hline
\end{tabular}

The other kinetic parameter not often reported is the order of kinetic especially when a general order approach is adopted for evaluating the crucial ones namely the activation energy and the frequency factor. An insight into deciding whether the glow curve of the dosimeter material understudy obeys the first order or the second order model is provided by the overall shape of the glow curve and its behavior when the absorbed dose is varied (Furetta and Weng, 1998). Here, a mere observation of the glow peak may not be sufficient due to the presence of a satellite peak in the higher temperature region as seen for $\beta$ $=1^{\circ} \mathrm{C} \mathrm{s}^{-1}$. Also established is the fact that first order peaks are stable with respect to the maximum peak position after varying the absorbed dose since as shown in the mathematical formulation (Randal and Wilkins, 1945) they are independent of the initial concentration of the charge carriers. Second order peaks, on the other hand, vary slightly $(\sim 1 \%)$ with increased absorbed dose due to a delay in the TL emission resulting from retrapping of the charge carriers (Garlick and Gibson, 1948). PI obviously does not obey any of those two models. The parameter in square brackets in the general order expression in Eq. (2) is a function of the kinetic order, $\mathrm{b}$ and from Eq. (2), one can write:

$\left[1+(b-1) \nabla_{M}\right]=\beta E_{A} / S k T_{M}^{2} \exp \left(E_{A} / k T_{M}\right)$

If one slots into the right-hand side of Eq. (13) the derived parameters and the appropriate heating rates and peak temperatures, one obtains $1.298 \pm$
$0.319,1.231 \pm 0.319$ and $1.316 \pm 0.319$ for $\beta=1{ }^{\circ} \mathrm{C}$ $\mathrm{s}^{-1}, 3^{\circ} \mathrm{C} \mathrm{s}^{-1}$ and $5^{\circ} \mathrm{C} \mathrm{s}^{-1}$, respectively. A plot of $\left[1+(b-1) \nabla_{M}\right]$ against $b$ shows that the best agreement is obtained for $1<b \leq 1.4$.

\section{CONCLUSION}

Kinetic parameters of the low temperature peak of Nigerian fluorite are reported in this work by applying the variable heating rate method using the general order expression suggested by Chen and Winer (1970). The activation energy and frequency factor values of $E_{\mathrm{A}}=1.31 \pm 0.06$ and $S$ $=(8.34 \pm 1.00) \times 10^{16} \mathrm{~s}^{-1}$ were obtained while kinetic order values greater than unity and up to 1.4 were found acceptable. Thermal quenching was investigated in this peak by also evaluating the activation energy using the initial rise method and an average value of $W=0.30 \pm 0.04 \mathrm{eV}$ was obtained for the three heating rates used. Its effect however was found to be more pronounced when the heating of $\beta=5^{\circ} \mathrm{C} \mathrm{s}^{-1}$ was employed with a value of $W=0.34 \pm 0.07 \mathrm{eV}$ and was manifested by a reduction in luminescence efficiency which can be interpreted as an increased probability of non-radiative recombination at the luminescence centers. The parameters reported here may differ slightly from other reports due to the presence of a shallow nearby satellite peak in this fluorite sample which may be more pronounced in other fluorite samples (Topaksu and Yazici, 2007). This is so as a more pronounced satellite peak in that region may affect the position of PI in which case the variable heating rates method may not be the 
appropriate approach to use.

\section{REFERENCES}

Balogun, F.A., Ojo, J.O., Ogundare, F.O., Fasasi, M.K., Hussein, L.A. 1999. TL response of a natural fluorite. Rad. Meas. 30: 759 - 763 .

Balogun, F.A., Tubosun, I.A., Akanle, A.O., Ojo, J.O., Adesanmi, C.A., Ajao, J.A. and Syrou, N.M. 1997. INAA in the determination of the elemental constituents of a natural fluorite. J. Radioanal. Nucl. Chem. 222: 35 38.

Bidyasagar, M., Singh, T.B., Barua, A.G. Gartia, R.K., 2014. Trap spectroscopy and thermoluminescence of $\mathrm{CaF}_{2}$ based TLDs. Ind.J. Pu. \& Appl. Phys. 52:13-18.

Chen, R., McKeever, S.W.S. 1997. Theory of thermoluminescence and related phenomena (World Scientific Publishing Co. Pte. Ltd.)

Chen, R., Pagonis, V., Lawless, J.L., 2016. Evaluated thermoluminescence trapping parameters -What do they really mean? Rad. Meas. 91: $21-27$.

Chen, R., Winer, A.A., 1970. Effects of various heating rates on glow curves. J. Appl. Phys. 41: $5227-5232$.

El-Kolaly, M.A., 1977. Thermoluminescence studies of natural and doped calcium fluoride phosphors. PhD thesis, University of Bombay, India.

Furetta, C., Kitis, G., Kuo, J.H., Vismara, L. Weng, P.S., 1997. Impact of non-ideal heat transfer on the determination of kinetic parameters. J. Lumin. 75: 341 - 351.

Furetta, C., Weng, P-S., 1998. Operational thermoluminescence dosimetry. (World Scientific Publishing Co. Pte. Ltd.).

Garlick, G.F.J., Gibson, A.F., 1948. Electron trap mechanisms of luminescence in sulphide and silicate phosphors. Proc. Phys. Soc. (London) 62: 574-590.

Hoogenstraaten, W., 1958. Electron traps in zincsulphide phosphors. Philips Res. Rep. 13: 515-693.

Ige, O.A, Olabanji, S.O., Ceccato, D., 2006a. PIXE analysis of muscovite samples from tourmaline bearing granite pegmatites of Southwestern Nigeria. J. Radioanal. \& Nucl. Chem. 268: 47-51.

Ige, A.O., Tubosun, I.A., Ogundare, F.O.,
Mokobia, C.E., Balogun, F.A., 2006b. TL response of muscovite samples from granite pegmatite of Ilesa and Ijero-Ekiti, Southwestern Nigeria. Rad. Meas. 41: 967 -970 .

Katona, T.,Osvay, M., Deme, S. , Kovács, A., 2007. Environmental dosimetry using highsensitivity TLdetectors. Radiat.Phys.Chem.76:1511-1514.

Kitis, G., Tuyn, J.W.N., 1998. A simple method to correct for temperature lag in TL glowcurve measurements. J. Phys. D: Appl. Phys. $31: 2065-2073$.

Latif, M.B., Fasasi, M.K., Balogun, F.A., 2012. Low dose TL characteristics of Nigerian fluorite. Rad. Meas. 47:182-184.

Maghrabi, M. Arafah, D.-H., 2003. Sensitization of the thermoluminescence response of $\mathrm{CaF}_{2}$ phosphors. Phys. Stat. Sol. (a) 195: 459 $-467$.

May, C.E., Partridge, J.A., 1964. Thermoluminescence kinetics of alphairradiated alkali halides. J. Chem. Phys. 40: $1401-1409$.

McKeever, S.W.S., 1988. Thermoluminescence properties of solids (Cambridge University Press).

Mesterházy, D., Osvay, M., Kovács, A., Kelemen, A., 2012. Accidental and retrospective dosimetry using TL method. Rad. Phys. \& Chem. 81:1525-1527.

Mokobia, C.E., Ogundare, F.O., Inyang, E.P., Balogun, F.A., Jonah, S.A., 2008. Determination of the elemental constituents of a natural dolerite using NIRR-1. Appl. Rad. \& Isot. 66: 1916 1919.

Mott, F.N., Gurney, M.A., 1948. Electronic Processes in Ionic Crystals, second ed. (Dover Publications Inc., NY).

Nambi, K.S.V., 1978. Influence of rare earth impurities on TL characteristics. Lecture1 given during A Specialist Seminar on Thermoluminescence Dating, July 3-8, 1978, Oxford University.

Oberhofer, M., Scharmann, A., 1981. Applied thermoluminescence dosimetry. Lectures of a course held at the Joint Research Centre, Ispra, Italy 12-16 Nov 1979.

Ogundare, F.O., Balogun, F.A., Hussain, L.A. 2004. Kinetic characterization of the 
thermoluminescence of fluorite. Rad. Meas. 38: $281-286$.

Ogundare, F.O., Balogun, F.A., Olowofela, J.A., Mokobia, C.E., Fasunwon, O.O., 2006. Thermoluminescence characteristics of natural dolerite. Nucl. Instr. \& Meth. Phys. Res. B 243: 156-160.

Osvay, M., Deme, S., 2006. Application of TL dosemeters for dose distribution measurements at high temperatures in nuclear reactors. Radiat. Prot. Dosi- metry 119: 271-275.

Polymeris, G.S., Kitis, G., Tsirliganis, N.C., 2006. Correlation between TL and OSL properties of $\mathrm{CaF}_{2}: \mathrm{N}$. Nucl. Instr. \& Meth. Phys. Res. B 251:133-142.

Randall, J.T., Wilkins, M.H.F., 1945. Phosphorescence and electron traps I. The study of trap distributions. Proc. Roy. Soc. (London) Series A184: 365-389.

Topaksu, M. Correcher, V., Garcia-Guinea, J.,
2016. Luminescence emission of natural fluorite and synthetic CaF2: Mn (TLD400). Rad. Phys. \& Chem. 119: 151-156.

Topaksu, M., Yazici, A.N., 2007. The thermoluminescence properties of natural $\mathrm{CaF}_{2}$ after $\beta$-irradiation. Nucl. Instr. \& Meth. Phys. Res. B 264:293-301.

Tugay, H., Yegingil, Z, Dogun, T., Nur, N., Yazici, N., 2009. The thermoluminescence properties of natural calcium fluoride for radiation dosimetry. Nucl. Instr. \& Meth. Phys. Res. B267:3640 - 3651.

Wintle, A.G., 1975. Thermal quenching of luminescence in quartz. Geophys. J. R. ash. Soc. 41:107-113.

Yazici, A.N., Chen, R., Solak, S., Yegingil, Z., 2002. The analysis of thermoluminescence glow peaks of $\mathrm{CaF}_{2}$ : Dy (TLD-200) after $\beta$ irradiation. J. Phys. D: Appl. Phys. 35: 2526 -2535 . 